\title{
Confidence in estimation of group norm as a function of subjective conformity'
}

SHLOMO BREZNITZ

THE HEBREW UNIVERSITY, JERUSALEM

Twenty-five groups of $S$ s were requested to state their opinion on certain issues, and at the same time to estimate the group norms on these issues. Confidence in the estimation was found to be related to subjective conformity rather than to the actual success in the estimation.

When Ss of a group are requested to state their opinion on a certain issue, and at the same time to estimate the modal response in the group (group norm) on that issue, it is possible to analyze each response in terms of objective conformity, subjective conformity, and knowledge of norm. These concepts may be operationally defined as follows:

Objective Conformity (OC): When Ss' response on an issue equals that of the majority of the group, that response would be termed $O C$.

Subjective Conformity (SC): When Ss' estimate of the group norm equals his own opinion, that response would be termed SC.

Knowledge of Norm (KON): When Ss' estimate of the group norm is correct, that response would be termed KON.

Taking a dichotomous item on which only the responses A or B can be given, and assuming that the majority in the group chooses A, for any individual, then, four patterns of responses are possible. These patterns and their analysis appear in Table 1.

As can be seen from Table 1, Pattern 1 indicates the presence of all the three attributes, and in a cohesive group, dealing with visible forms, Pattern 1 responses can be expected to be the most frequent ones. Patterns 2-4, on the other hand, indicate that these attributes are not necessarily complementary; with Pattern 2 having only SC, Pattern 3 OC "without awareness," and Pattern 4 being clearly the pattern of a nonconformist.

Let us assume now that in addition to stating on each item his own opinion and estimating the group norm, the $\mathrm{S}$ is requested to give his degree of confidence in his estimation of the norm. Which of the attributes would account for most of the variance in confidence responses? The major aim of this study was to subject this question to an empirical test.

Within the framework of learning theories one deals with statements of confidence as conditioned responses. The internal cues of confidence have been probably related in the past to molar events such as "being right," "guessing wrong," etc., and it is conceivable that Ss will learn the contingency between feelings of confidence and being right. A person will thus
Table 1. Possible patterns of responses and the presence $(t)$ or absence $(-)$ of $(\mathrm{OC}),(\mathrm{SC})$, and $(\mathrm{KON})$. Norm $=A$.

\begin{tabular}{lccccc} 
Pattern & $S^{\prime}$ opinion & $S^{\prime}$ estimate of norm & (OC) & (SC) & (KON) \\
\hline 1 & A & A & + & + & + \\
2 & B & B & - & + & - \\
3 & A & B & + & - & - \\
4 & B & A & - & - & + \\
\hline
\end{tabular}

"know" whether he is on the right track even before the actual feedback. Such a "fractional antecedent goal response"' would be expected to relate primarlly to the success or failure of the estimation of the norm, i.e., KON. This would be in line with Adam's (1961) analysis of the problem of confidence.

One may expect, on the other hand, a positive relationship between conformity and feeling of confidence. Such a relationship is actually postulated sometimes as the main factor in conformity, since confidence is assumed to be one of the chief rewards of conforming behavior and group belongingness (e.g., Newcomb, 1943; Asch, 1952; Hoffman, 1957; and Bogdonoff et al, 1961). The question then becomes whether such feelings of confidence based on conforming behavior would be generalized to confidence in KON. Another question would be to determine which type of conformity, OC or SC, is more important in this respect.

\section{Subjects and Procedure}

The Ss in this study were soldiers in the Israelf army who had spent at least 3 months in intensive interaction within the framework of small groups. There were 25 groups with sizes ranging between 5 and 10, and altogether including $176 \mathrm{Ss}$.

Twenty dichotomous items dealing with opinions concerning the army life (e.g., the quality of the food in the camp, the relative importance of morale and discipline, the relative intensity of two different punishments, etc.) on which a lot of interpersonal communication could have been expected within the groups, and opinions on issues irrelevant to the group life (e.g., color preference, attitude towards television, moral statements, etc.) were used. In this way it

Table 2. Distribution of confidence response according to response pattems

\begin{tabular}{lcccc} 
Pattern & 1 & 2 & 3 & 4 \\
\hline$\%$ Confidence & 66 & 60 & 33 & 40 \\
$\%$ Guess & 34 & 40 & 67 & 60 \\
\hline
\end{tabular}


Table 3. Distribution of confidence responses and (SC)

\begin{tabular}{lccr} 
& Confidence & Guess & Total \\
\hline (SC)+ & 1087 & 595 & 1682 \\
$(\mathrm{SC})_{-}$ & 132 & 237 & 369 \\
Total & 1219 & 832 & 2051 \\
\hline
\end{tabular}

was hoped to obtain data on norms of varying visibility (Merton, 1957). The questionnaire was administered to all $\mathrm{Ss}$ of a group simultaneously in order to avoid communication and ensure that in estimating the group norm all Ss would relate to the same people. On every item Ss stated their own opinion, the estimated group norm, and lastly, their level of confidence, using the dichotomy confidence/guess. It was explicitly stated that the information would be seen by the $E$ alone.

Results

In each group the modal response to an item was used as the basis for the computation of $\mathrm{SC}, \mathrm{OC}$, and KON of all the group members. The analysis was made in terms of the four response patterns described in Table 1. The distribution of confidence responses according to these patterns is presented in Table 2. The percentages are based on total number of responses (i.e., Ss $x$ items).

Table 2 clearly indicates that $\mathrm{SC}$ is the major attribute related to confidence. Moving from Pattern 1 to Pattern 2, it appears that there is practically no loss in confidence, although Pattern 2 has no OC and no KON. Comparison with Patterns 3 and 4 which lack SC shows that confidence in KON drops dramatically.

A test of statistical significance was done using a group (and not a response) as a unit of analysis. In each group the attribute with the strongest relationship with confidence was established, and a sign test performed. In 20 groups SC was the chief factor, in four $K O N$, and in one OC, $p<.01$. The same sort of sign test using a single $S$ as a unit of analysis again supported this finding $(p<.001)$. It appears, therefore, that $\mathrm{SC}$ is systematically the best predictor of confidence in KON.

In order to throw some additional light on the type of relationship between $\mathrm{SC}$ and confidence in $\mathrm{KON}$, Table 3 presents the distribution of these two variables.

Since SC+ is the more frequent response both in cases of confidence and in cases of guess, confidence response cannot predict SC. On the other hand, SC has high predictive value of confidence responses. This suggests that SC is probably the independent and confidence the dependent variable.

\section{Discussion}

The data of this study indicate that confidence in estimation of group norms is not at all related to actual success in this estimate. Subjective conformity, on the other hand, gives the $S$ confidence in his estimates. In attempting to analyze this finding, one kind of argument could have been that $\mathrm{SC}$ is a pattern which Ss would use only when they are confident in KON, since otherwise they would appear to be overconforming. Table 3, however, does not support this interpretation and seems to imply that the causal chain is reversed, i.e., that SC precedes confidence. This would be in line with the notion of a general feeling of confidence based on conformity, which was generalized to the estimation of the group norm.

The fact that $\mathrm{SC}$ rather than $\mathrm{OC}$ is the main factor implies greater impact of intrapersonal rather than interpersonal factors in the determination of confidence in group norm.

One may further speculate that this relationship would actually be an obstacle in the acquisition of the "true" group norm. SC giving rise to confidence in group norm would reduce the chances of additional information seeking. In this respect, therefore, it would be rather the nonconformist who will be more open to information concerning the group norm, and consequently exposed to factors which might change his behavior.

\section{References}

Adams, J. K., \& Adams, P. A. Realism of confidence judgments, Psychol. Rev., 1961, 68, 33-45.

Asch, S. E. Social psychology. New York: Prentice-Hall, Inc., 1952. Bogdonoff, M. D., Klein, R. F., Estes, E. H., Jr., Shaw, D. M., \& Back, K. W. The modifying effect of conforming behavior upon lipid responses accompanying CNA arousal. Clin. Res., 1961. $9,135$.

Hoffman, M. L. Conformity as a defense mechanism and a form of resistance to genuine group influences. J. Pérs., 1957, 25, 412424.

Merton, R. K. Social thcory and social structure. Glencoe, Illinois: Free Press, 1957.

Newcomb, T. M. Personality and social change. New York: Dryden Press, 1943.

\section{Note}

1. The author is indebted to Dr. E. O. Schild of the Hebrew University, Jerusalem, for his helpful suggestions. 